\title{
The Uncertainty of an Assessment Procedure for the West Greenland Stock of Northern Shrimp, Pandalus borealis (Krøyer)
}

\author{
Carsten Hvingel ${ }^{1}$ and Michael C. S. Kingsley \\ Pinngortitaleriffik - Greenland Institute of Natural Resources \\ P.O. Box 570, DK-3900 Nuuk, Greenland
}

\begin{abstract}
The shrimp (Pandalus borealis) resource off West Greenland was assessed by fitting, to four fleets operating over different periods, separate CPUE (catch-per-unit-effort) models, which were then combined. A logistic model of population dynamics was then fitted to these data and a standard trawl survey series. Uncertainty was estimated by a jackknife procedure - leaving out one year's data at a time - in several forms: omitting data from all steps in the process or only from the last step of fitting the production model; or omitting data either for one year at a time at each point in the series or for a sequence of years at the start of the series.

Initial results from jackknifing the entire procedure gave partial estimates of optimal fishing mortality scattered around 0.5 per year. The sustainable catch was 108000 tons and had a $62 \%$ coefficient of variance $(\mathrm{CV})$ and ranged from $8 \%$ lower to $52 \%$ higher than the value based on all the data. Omitting the first year's data created an outlier with a $47 \%$ lower sustainable fishing mortality. When jackknifing only the input to the logistic population model, the optimal fishing mortality retained a CV of near $63 \%$, but the CV of sustainable catch fell to about $19 \%$ (ranging from $8 \%$ lower to only $7 \%$ higher). Much of the variation in estimated sustainable catch therefore appeared due to uncertainty in the standardized CPUE series. However, omitting the first year's data continued to give an outlying point, so the effect of leaving out the first year's data was investigated further.
\end{abstract}

When the experiment was repeated with the first two data points permanently omitted, the estimate and uncertainty of MSY decreased to around 82000 tons with a CV near $18 \%$, while the variation in sustainable fishing mortality and in standing stock increased. Also, there was little difference whether the jackknife procedure included the General Linear Modelling fitting of the CPUE series or whether points were simply omitted from a single series based on all the years' data. Thus particular properties of the data points appeared to have significant effects.

The jackknife procedure appears useful for examining the reliability of this standard method of fishery assessment, and these results indicate that the uncertainty of such results may be unpredictable, large, variable between model parameters, and difficult to assign to any particular step in the procedure.

Key words: $\quad$ assessment, biomass-dynamic model, jackknife, shrimp, West Greenland

\section{Introduction}

The northern shrimp (Pandalus borealis) occurs off West Greenland in NAFO Div. 0A and 1A-1F, mostly in water from 150 to $600 \mathrm{~m}$ deep. The shrimp fishery started in inshore areas in 1935. After 1970 an offshore fishery developed and landings increased from about 10000 tons to a level around 70000 tons in the 1990s (Fig. 1). Catches in offshore areas have been restricted since 1977 by the annual setting of a Total Allowable Catch (TAC). The stock component in the inshore areas is protected by effort restrictions, i.e. no access for vessels larger than 80 GRT and a limit on the number of licences issued to vessels below 80 GRT. Since 1997 a TAC was also imposed for the inshore areas. The TAC is usually caught.

1 Author to whom correspondence should be addressed, at: Norwegian College of Fishery Science, Dept. of Marine and Freshwater Biology, University of Tromsø, Breivika, 9037 Tromsø, Norway. Tlf +47 776460 22; Fax: +47 77646020 ; carstenh@nfh.uit.no. 


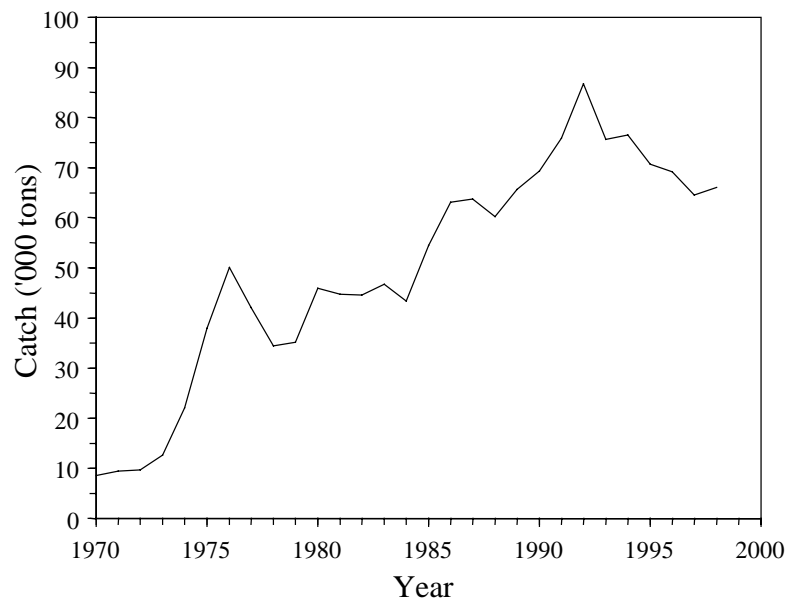

Fig. 1. Catch ('000 tons) of the shrimp fishery off West Greenland 1976-98 (from Hvingel, MS 1999).

The stock is assessed as a single population (NAFO, 2000). Information available for evaluating the stock status comprises data from the fishery on catch, effort and standardized catch rates, biomass indices from research surveys, and data on the size composition of the stock. No analytical models are currently used in the assessment of the stock and fishing mortality is unknown. Sequential Population Analysis (SPA) has been tried (Savard et al., MS 1991), but older ages cannot be distinguished well enough for this technique to be reliable. An aggregate model must therefore be used. Such models are usually of the stockproduction type (e.g. Shaefer, 1954) and describe stock dynamics simply in terms of rates of change of total biomass, rather than by the details of age-specific growth and mortality (see Hilborn and Walters, 1992, for a review of production models). These models often provide results similar to age-structured models (Ludwig et al. 1985; 1989; Prager et al., 1996).

Biomass-dynamic models are widely used in marine stock assessments. They have been applied to a broad spectrum of species ranging from whales (e.g. Donovan, 1989, p. 145-199) through marine fish (e.g. Stevenson et al., 1997; Horbowy, 1996; Mathews and Samuel, 1991) to lobster (Chen and Montgomery, 1999) and sea cucumber (Bradbury et al., 1996). They are, however, most commonly used in assessments of tuna and tropical fish stocks (e.g. Anon., 1999). In the late 1970s and early 1980s Skúladóttir (1979, MS 1985) applied an equilibrium-type production model to some Icelandic shrimp stocks, but otherwise only recently have biomass-dynamic models been tried on stocks of northern shrimp (Cadrin et al., 1999; Cadrin and Skúladóttir, MS 1998; Berenboim and Korzhev, MS 1997; Stefánsson et al., MS 1994).

For fitting a biomass-dynamic model, the minimum data requirements are one or more time series of biomass indices and concurrent catches. Catch-rate indices developed by standardising catch performance(s) of individual vessels or vessel-groups over time (Gavaris, 1980; Kimura, 1981) are assumed to index biomass and may be used as one set of inputs. There may be concerns as to whether this assumption is in general correct (see e.g. Cooke and Beddington, 1985), which will not be dealt with in this paper. However, even if it is, there is a further concern as to the effect that uncertainty or error in the input series of catcheffort ratios (or other biomass indices) may have on the estimates of stock-dynamic parameters generated by a biomass-dynamic model. In the present article we use a jackknife method (Efron, 1982) to explore this aspect of the uncertainty of the results arising from stock-dynamic modelling of a stock of northern shrimp.

The jackknife re-sampling procedure provides an approach to exploring both the magnitude and the subject of the uncertainty. It allows not only, through the summary statistics, some quantification of the uncertainty of a conclusion, but also an investigation of the influence of individual data points on the result. The procedure mimics a very possible application of a biomass dynamic model to series of data, in which the series might have started a year later or missed a year's data for reasons outside the control of the assessment process, and as such is relevant to the use of such models in assessments.

In order to explore the uncertainty of stock parameter estimates from the biomass-dynamic model, we fitted a non-equilibrium logistic production model of the Schaefer type to two series of biomass indices for the West Greenland stock of northern shrimp: a standardized catch-rate index from the commercial fishing fleets and a survey series. The commercial catch-rate series was itself a composite of four partly overlapping series. The aim of this study was to determine the reliability of the biomass-dynamic parameter estimates resulting from standardising and combining four catch-rate series, and fitting a logistic population model.

\section{Materials and Methods}

The assessment procedure used consisted of constructing a CPUE (catch-per-unit-effort) based index of stock biomass for 1976-98 (Hvingel et al., 2000) 
and fitting a model of stock biomass dynamics to these data and a standard trawl survey series (Carlsson et al., MS 1998) for 1987-98. Total reported catch in Subarea 0+1 (Hvingel, MS 1999) was used as yield data.

\section{CPUE data}

The CPUE data came from four fleets through logbooks, which included about one million hauls. Standardized CPUE index series, corrected for differences in vessel fishing power and varying temporal and geographical distribution of fishing effort through the year, were derived for each fleet using General Linear Modelling (GLM) techniques (Gavaris, 1980; Kimura, 1981). The models were of the form:

$$
\begin{aligned}
& \ln \left(C P U E_{i j k l}\right)=\ln (u)+\ln \left(A_{i}\right)+\ln \left(S_{j}\right)+\ln \left(V_{k}\right) \\
& \quad+\ln \left(Y_{I}\right)+e_{i j k l}
\end{aligned}
$$

where $C P U E_{i j k l}$ is the mean CPUE for vessel $k$, fishing in area $i$ in month $j$ during year $l ; \ln (u)$ is overall mean $\ln (C P U E) ; A_{j}$ is effect of the $i^{t h}$ area; $S_{j}$ is the effect of the $j^{\text {th }}$ month; $V_{k}$ is the effect of the $k^{\text {th }}$ vessel; $Y_{l}$ is the effect of the $l^{\text {th }}$ year; $e_{i j k l}$ is the error term assumed to be normally distributed. The standardized CPUE indices are the antilog of the year coefficient.

A single combined CPUE index was then derived by fitting a single series to the four separate CPUE series, minimising a sum of squares weighted by the area, $a_{i}$, fished by each fleet. The individual CPUE series for the $i^{t h}$ fleet, $\mu_{i j}$, was assumed to reflect an overall biomass series, $Y_{j}$, and a constant fleet coefficient, $v_{i}$, so that $\mu_{i j}=v_{i} Y_{j}+e_{j k}$. Hence, the combined index was constructed by fitting $v_{i}$ and $Y_{j}$ to minimise:

$$
\sum_{i} a_{i} \sum_{j}\left(\mu_{i j}-v_{i} Y_{j}\right)^{2}
$$

The resulting CPUE series is shown in Fig. 2. A complete description of the procedure for constructing of the CPUE index is given in Hvingel et al. (2000).

\section{Biomass-dynamic model}

A standard logistic model of biomass dynamics was used, which in its differential form is:

$$
\frac{d B}{d t}=r B_{t}-\frac{r B^{2}}{K}-C_{t}
$$

where $B_{t}$ is 'biomass' (tons) in year $t, r$ is 'intrinsic rate of growth' (per year), $K$ is 'carrying capacity' (tons), and $C_{t}$ is 'instantaneous catch rate' (tons per year).

The parameters $(r, K$, and a series of yearly values for $B$ ) were estimated using the ASPIC modelling software (Prager, 1994, 1995). This program fits a trial set of biomass-dynamic parameters and constructs the consequent stock biomass trajectory from the joint action of the supposed dynamics and the observed catches. These calculated annual biomass values are compared with the input index series - scaled by catchability coefficients - and the parameter estimates are adjusted (by simplex optimisation - Nelder and Mead, 1965) to minimise the sum of squares of the differences. Parameters, important for management, that can be derived from the estimates of $r$ and $K$ are: the maximum sustainable catch $(\mathrm{MSY}=\mathrm{Kr} / 4)$ and the associated standing stock $\left(B_{M S Y}=K / 2\right)$ and fishing mortality $\left(F_{M S Y}=r / 2\right)$, assuming that the logistic model is appropriate.

An initial ASPIC run including all data, in which the CPUE and survey series were iteratively reweighted based on initial mean square errors, suggested a weighting of the CPUE: survey of 3.05:1. This weighting was kept fixed in all subsequent runs. The used setup of ASPIC is shown in Table 1.

\section{Jackknifing}

We used a standard jackknife (Efron, 1982) to examine possible error in the estimates of biomass dynamics parameters. A set of "partial estimates" were created either by a repeating procedure of deriving the combined CPUE index series and feeding it to the production model, leaving out one year of data at a time or by repeatedly leaving out one data point at a time from the fixed CPUE series and/or survey series. The complete series of reported catch data was included in all runs: because complete catch data was necessary to calculate the estimated stock trajectory and the catches were in any case assumed known without error. The jackknife estimate of a parameter, $Y^{\prime}$, and its standard error, $s \hat{e}$, is defined by:

$$
\hat{Y}^{\prime}=\sum_{j=1}^{n} \frac{Y_{j}{ }^{\prime}}{n} \text { and } s \hat{e}=\left[\frac{n-1}{n} \sum_{j=1}^{n}\left(Y_{j}^{\prime}-\hat{Y}^{\prime}\right)^{2}\right]^{1 / 2}
$$

where $Y_{j}^{\prime}$ is the partial estimate obtained with the $j^{\text {th }}$ year of data deleted and $n$ is the number of years of data included. (The jackknife method also offers a possibility of correcting for sample-size bias, which we did not use).

We made two groups of run sets: A and B (see Table 2). In the first set of runs (A1) standardized indices for the commercial catch-rate series for 1976-98 were estimated by the methods of Hvingel et al. (2000), but leaving out one year of data at a time; i.e. a CPUE series was computed omitting the data for all fleets active in 1976, then the 1976 data was replaced and 
TABLE 1. (A) Setup, (B) Goodness-of-fit and (C) parameter estimates from an ASPIC-run using the complete 1976-98 data set. The bias corrected parameter estimates and their uncertainty are obtained by the ASPIC bootstrapping procedure. $\mathrm{B} 1 \mathrm{R}=\mathrm{B} 1$ ratio $=$ ratio of initial biomass (biomass in 1976) to $B_{M S Y}$ $\left(B_{M S Y}=\mathrm{K} / 2\right) . \mathrm{SSE}=$ sum of squared errors, $\mathrm{MSE}=$ mean squared errors, $\mathrm{CL}=$ confidence limit, $\mathrm{IQ}=$ interquartile.

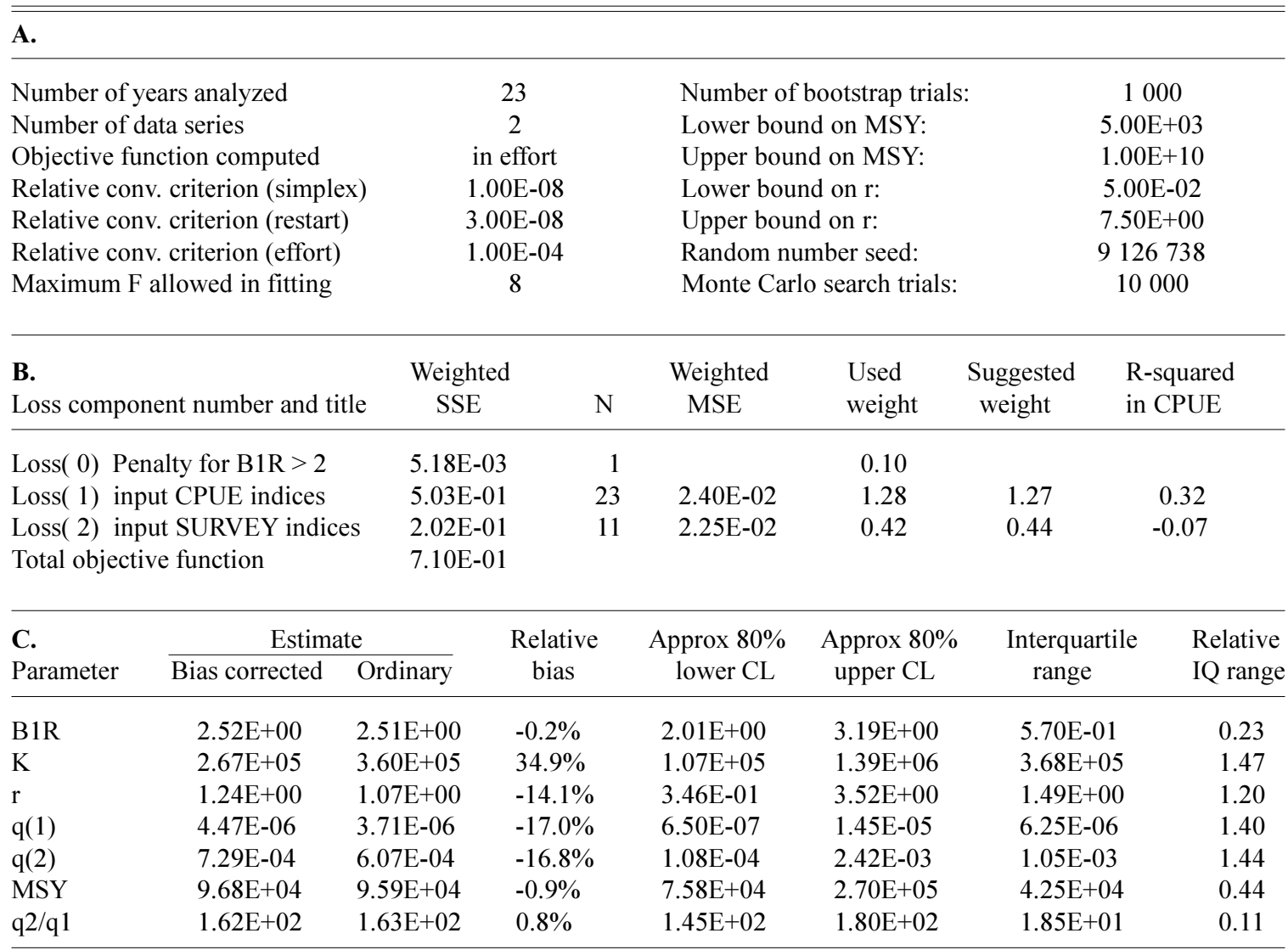

TABLE 2. Coefficients of variation (CV) in percent, means and range of the partial estimates of maximum sustainable yield (MSY) and standing stock biomass $\left(B_{M S Y}\right)$ in thousand tons and sustainable fishing mortality $\left(F_{M S Y}\right)$ as estimated by different jackknife procedures using (A) the complete 1976-98 data set and (B) the reduced 1978-98 data set.

\begin{tabular}{|c|c|c|c|c|c|c|c|c|c|}
\hline \multirow[b]{2}{*}{ A. 1976-98 DATA } & \multicolumn{3}{|c|}{$\mathrm{CV}(\%)$} & \multicolumn{3}{|c|}{ Range ('000 tons) } & \multicolumn{3}{|c|}{ Mean ('000 tons) } \\
\hline & MSY & $B_{m s y}$ & $F_{m s y}$ & MSY & $B_{m s y}$ & $F_{m s y}$ & MSY & $B_{m s y}$ & $\mathrm{~F}_{\text {msy }}$ \\
\hline 1. Both series jackknifed & 62 & 100 & 63 & $88-146$ & $151-321$ & $0.43-0.65$ & 108 & 215 & 0.51 \\
\hline 2a. Fixed CPUE and survey jackknife & d 19 & 79 & 57 & $88-103$ & $151-206$ & $0.45-0.65$ & 96 & 183 & 0.53 \\
\hline 2b. Survey series jackknifed & 3 & 12 & 12 & 94-97 & $163-190$ & $0.50-0.58$ & 96 & 178 & 0.54 \\
\hline 2c. CPUE series jackknifed & 46 & 78 & 57 & $88-126$ & $151-248$ & $0.45-0.65$ & 103 & 198 & 0.52 \\
\hline 3. Fixed CPUE series jackknifed & 18 & 77 & 55 & $88-103$ & $151-206$ & $0.45-0.65$ & 96 & 183 & 0.53 \\
\hline
\end{tabular}

B. $1978-98$ DATA

$\begin{array}{lrrrrrrrrr}\text { 1. Both series jackknifed } & 19 & 83 & 89 & 76-92 & 130-278 & 0.27-0.65 & 82 & 204 & 0.42 \\ \text { 2a. Fixed CPUE and survey jackknifed } & 18 & 58 & 91 & 76-94 & 130-296 & 0.28-0.65 & 84 & 240 & 0.36 \\ \text { 2b. Survey series jackknifed } & 6 & 10 & 14 & 82-88 & 230-259 & 0.31-0.38 & 84 & 243 & 0.35 \\ \text { 2c. CPUE series jackknifed } & 17 & 83 & 88 & 77-92 & 130-258 & 0.31-0.65 & 82 & 205 & 0.42 \\ \text { 3. Fixed CPUE series jackknifed } & 15 & 57 & 89 & 80-94 & 130-296 & 0.29-0.65 & 85 & 240 & 0.36\end{array}$


another series was computed omitting the data for 1977 and so on. Obviously, there was a missing value for the year whose data was left out, but also, the values for all the other years altered as well. The stockdynamics model was then fitted to each of the resulting 23 data sets, the same year's value also being omitted from the series of trawl survey biomass indices. The variation of obtained partial estimates indicated the uncertainty in the overall assessment procedure.

A second set of runs (A2a-c, Table 2) was done to decompose the overall uncertainty into components due to: 2 a. total process error of the production model; $2 b$. the effect of including the survey series; and $2 \mathrm{c}$. the procedure of constructing the CPUE series. The runs in set 2 a were thus carried out using the CPUE series computed from all years' catch and effort data and repeatedly omitting one year at a time both from this unchanging series and the survey series in the input to the production model. Run set $2 \mathrm{~b}$ was done like the previous except that the CPUE series was always entered in its complete length, i.e. only the survey data was jackknifed. In run set $2 \mathrm{c}$ all the survey data was always entered and the catch and effort data was jackknifed and the CPUE series recalculated before entered in the production model.

It is not possible to decompose completely the uncertainty seen in run set $2 \mathrm{c}$ because when the process of constructing the CPUE series is jackknifed a missing point is ipso facto generated for the CPUE series input to the model. However, a third set of runs (run set A3) was carried out in which the fixed CPUE series was jackknifed while we always kept all the survey data. The variation of these results indicated the uncertainty in the parameter estimates due only to the uncertain fit of the stock-dynamic model to the series of biomass indices and to the known catches.

The results of the first group of run sets (A1-3) all indicated that the first year had a significant influence on the result, i.e. when the 1976 data point was omitted, the result obtained never lay within the scatter pattern obtained when the other years were in their turn left out (Fig. 4). We examined if this was a special feature of the 1976 data point, or whether it indicated an exceptional influence of the first year's data whatever it was. To do so, we made a set of runs in which we deleted consecutive years of data on catch and effort from the entire assessment procedure, i.e. the first data series had all the data, the second had data only from 1977, the third only from 1978, and so on. The shortest series we tried had data from 1986 onwards. As this investigation suggested that both the
1976 and 1977 data had a significant influence on model output we made a second group of runs (run B1-B3, Table 2) like the five sets of runs described above but with the 1976-77 data permanently deleted.

\section{Results}

Running the assessment procedure on the complete data set gave an estimated MSY of about 96000 tons at a standing stock $\left(B_{M S Y}\right)$ of 180000 tons (Table 1C). The CV (coefficient of variation) estimated by the bootstrapping procedure of ASPIC (Prager, 1994) was $33 \%$ and $109 \%$, respectively. This is an estimate of model process error. The bootstrap analysis suggested moderate bias of the estimates of $r$ and $K(-13 \%$ and $+37 \%$ ), but little bias $(<1 \%)$ of their product MSY $(\mathrm{MSY}=K r / 4)$. However, the production model was only able to capture the overall trend in the biomass indices (Fig. 2) and thus explained no more than $32 \%$ of the variance in the CPUE series and $7 \%$ of that in the survey series (Table 1B). A plot of the residuals against time thus showed groups of points alternately shifting from positive to negative as the model cuts a "running average" through the fluctuating observed values (Fig. 3).

The uncertainty in the overall assessment procedure is indicated by run set A1 (Table 2 and Fig. $4)$. When the entire procedure was jackknifed variable values of MSY (CV 62\%) and $B_{M S Y}(100 \%)$ were obtained. This variation was positively skewed (Fig. 4 ). The ratio between MSY and $B_{M S Y}$, i.e. the values of sustainable fishing mortality, were scattered near a

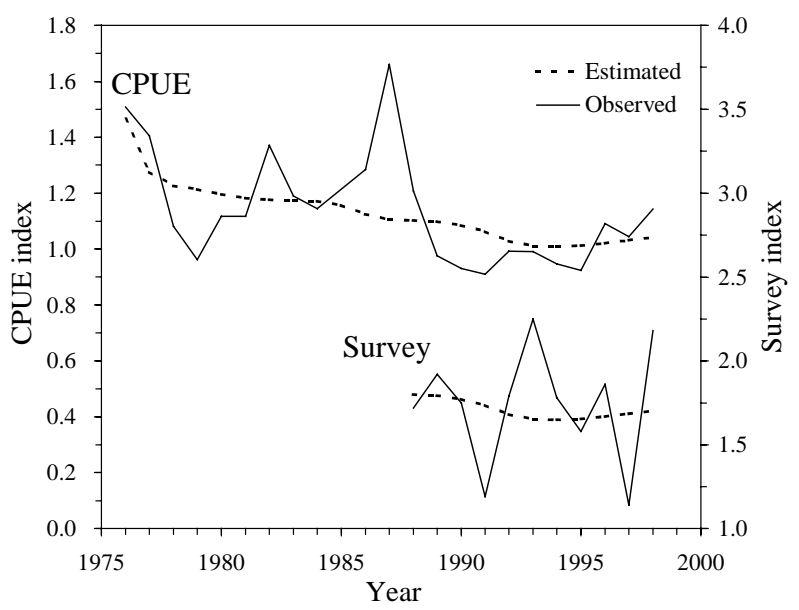

Fig. 2. Observed catch-rate (i.e. standardized by the methods of Hvingel et al. (2000)) and survey indices (both in relative units) and the corresponding series estimated by the production model. 
central value of 0.5 per year. Omitting the survey and CPUE data for the first year (1976) gave different results: when this year was omitted, $F_{M S Y}$ was 0.29 per year, and $B_{M S Y}$ was 320000 tons.

In run set A2a, jackknifing was limited to omitting one year's data at a time from the input to the production model, i.e. simulating no propagation of error from the procedure of constructing the CPUE series to the parameter estimates of the production model. This reduced the variability of MSY and $B_{M S Y}$ to about $1 / 3$ of the total variation as calculated in the previous run (Table 2). The scatter was evenly distributed around 96000 tons i.e. the value obtained from using all the years' data (Fig. 4). Omitting the 1976 data still gave an outlying result with low sustainable fishing mortality.

The survey data seemed to generate a relatively small amount of variation (run set A2b). Therefore, when we removed the variance contribution of the survey data (A2c) from the total variance (A1) the difference was small. The CV of MSY declined by $1 / 4$ and the skewness of the partial estimates of MSY was somewhat reduced (Fig. 5). When the survey influence on the process error (A2a) was removed in run set A3 changes were insignificant and the CV of MSY remained at about 19\% (Table 2 and Fig. 4 and 5).

The investigation of the influence of the first data point showed that when the data of 1976 and 1977 had been omitted, MSY decreased from about 96000 tons

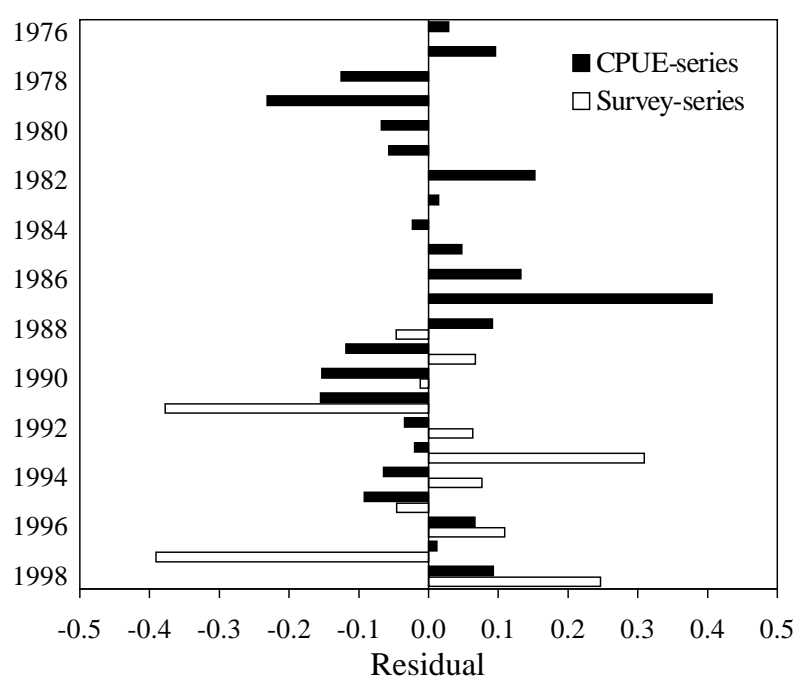

Fig. 3. Difference between observed and estimated values of the CPUE and survey series (see Fig. 2) shown as residuals in the logarithmic values. and stabilised around 84000 tons as further shortening of the data series took place. However, a run of the entire assessment procedure, but with the 1976-77 data permanently deleted, did not show an improved fit of

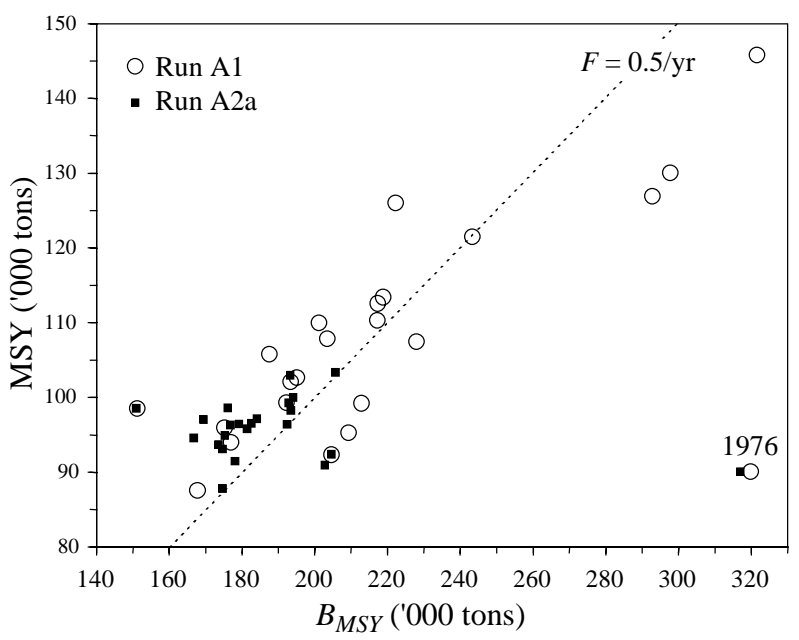

Fig. 4. Partial estimates of Maximum Sustainable Yield (MSY) and the corresponding standing stock biomass $\left(B_{M S Y}\right)$ in thousand tons from run set A1 and A2a (see text). The 0.5 isocline of fishing mortality $(F)$ is shown by the dotted line. The point marked 1976 is the result obtained when the 1976 data was left out.

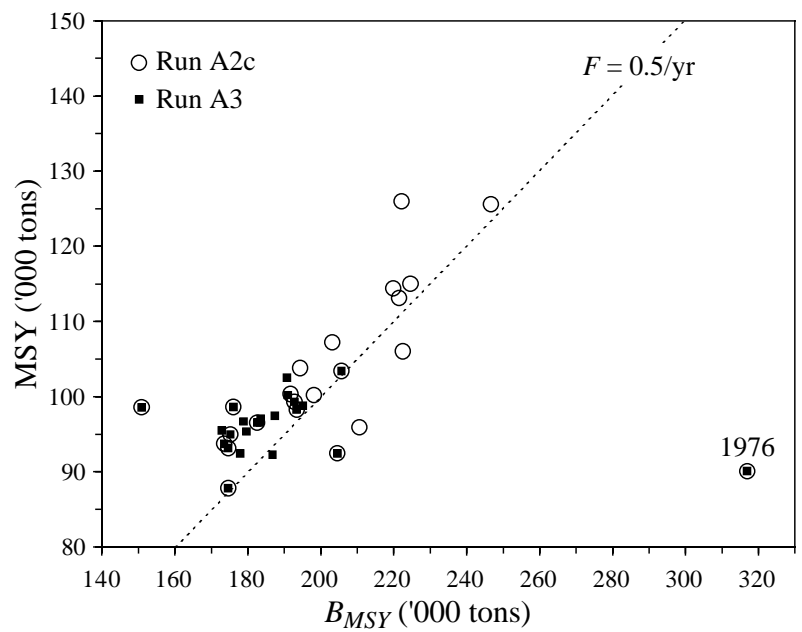

Fig. 5. Partial estimates of Maximum Sustainable Yield (MSY) and the corresponding standing stock biomass $\left(B_{M S Y}\right)$ in thousand tons from run set A2c and A3 (see text). The 0.5 isocline of fishing mortality $(F)$ is shown by the dotted line. The point marked 1976 is the result obtained when the 1976 data was left out. 
the model. On the contrary R-squared for the CPUE and survey series was now $23 \%$ and $8 \%$ respectively. The resulting parameter estimates of the production model are shown in Table 3.

When the run sets $\mathrm{A} 1$ and $\mathrm{A} 2 \mathrm{a}$ were repeated without the 1976-77 data, the CV of the MSY was reduced to $19 \%$ when the entire processes were jackknifed (B1) - not very different from when only the input to the production model was jackknifed (B2a, see Table 2). However, at the same time variation of the $B_{M S Y}$ remained at the same level and giving an increase in the variation of the MSY/B $B_{M S Y}$-ratio, i.e. $F_{M S Y}$ (Table 2 and Fig. 6). Run sets B2c and B3 showed rather similar results, while run set $\mathrm{B} 2 \mathrm{~b}$ again confirmed that a small amount of variance originated from fitting the model to the survey data.

\section{Discussion}

The variation between the partial estimates from jackknifing the entire assessment process (Fig. 4 and 6) is a measure of the uncertainty associated with deductions about sustainable fishing policies based on this kind of model fitting. From the initial investigations about $2 / 3$ of the uncertainty in the estimated MSY and $1 / 4$ of the $B_{M S Y}$ seemed to arise from uncertainty in fitting the CPUE series to the catch and effort data from four fleets. Fitting the production model to the CPUE and survey data was responsible for $1 / 3$ and $3 / 4$ of the uncertainty in MSY and $B_{M S Y}$, respectively. The production model appeared sensitive to the first data point in the CPUE series. When this was omitted, very different results were obtained. Further analyses however suggested that this was not a characteristic of being the first point in the data series but rather a special feature of the 1976 and also 1977 data points. In the subsequent analyses where the 1976-
77 data were omitted only $1 / 20$ of the uncertainty in $M S Y$ and about $1 / 3$ of the uncertainty in $B_{M S Y}$ appeared to come from the CPUE-series and the remaining 19/ 20 and $2 / 3$ were due to model process error.

The uncertainty of the parameter estimates obtained from fitting the production model may originate from various sources. When the fundamental assumption of the data being from a single closed population is fulfilled, the reliability of the estimated parameters are dependent on: 1) the ability of the model to describe the dynamics of the population, 2) the contrast in the data, i.e. the historical variation in stock size and fishing effort, and 3) the uncertainty of the stock biomass indices. A valid model also requires that all the biomass indices used are linearly related to

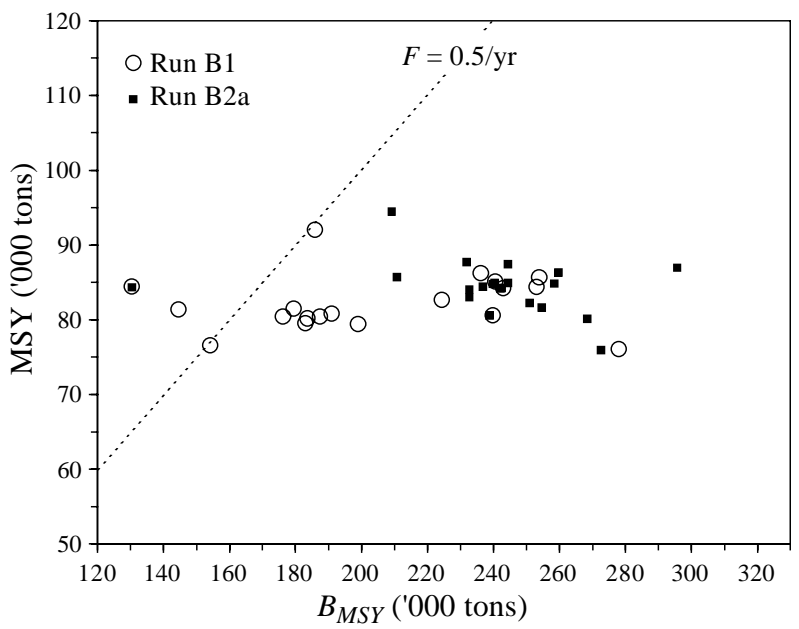

Fig. 6. Partial estimates of Maximum Sustainable Yield (MSY) and the corresponding standing stock biomass $\left(B_{M S Y}\right)$ in thousand tons from run set B1 and B2a (see text). The 0.5 isocline of fishing mortality $(\mathrm{F})$ is shown by the dotted line.

TABLE 3. Bias corrected parameter estimates and their uncertainty obtained by the ASPIC bootstrapping procedure using the reduced $1978-98$ data set. $\mathrm{B} 1 \mathrm{R}=$ ratio of initial biomass (biomass in 1978) to $B_{M S Y}\left(B_{M S Y}\right.$ $=\mathrm{K} / 2$ ).

\begin{tabular}{lccccccc}
\hline \hline & \multicolumn{2}{c}{$\begin{array}{c}\text { Estimate } \\
\text { Parameter }\end{array}$} & Bias corrected & Ordinary & Relative & Approx 80\% & Approx 80\% \\
bias & lower CL & upper CL & $\begin{array}{c}\text { Interquartile } \\
\text { range }\end{array}$ & $\begin{array}{c}\text { Relative } \\
\text { IQ range }\end{array}$ \\
\hline B1R & $1.48 \mathrm{E}+00$ & $1.33 \mathrm{E}+00$ & $-10.4 \%$ & $1.18 \mathrm{E}+00$ & $2.59 \mathrm{E}+00$ & $8.82 \mathrm{E}-01$ & 0.59 \\
$\mathrm{~K}$ & $5.00 \mathrm{E}+05$ & $4.89 \mathrm{E}+05$ & $-2.2 \%$ & $1.83 \mathrm{E}+05$ & $1.41 \mathrm{E}+06$ & $4.40 \mathrm{E}+05$ & 0.88 \\
$\mathrm{r}$ & $6.36 \mathrm{E}-01$ & $6.91 \mathrm{E}-01$ & $8.7 \%$ & $1.66 \mathrm{E}-01$ & $1.72 \mathrm{E}+00$ & $6.50 \mathrm{E}-01$ & 1.02 \\
$\mathrm{q}(1)$ & $2.67 \mathrm{E}-06$ & $2.90 \mathrm{E}-06$ & $8.7 \%$ & $1.17 \mathrm{E}-06$ & $6.53 \mathrm{E}-06$ & $2.31 \mathrm{E}-06$ & 0.86 \\
$\mathrm{q}(2)$ & $4.35 \mathrm{E}-04$ & $4.67 \mathrm{E}-04$ & $7.5 \%$ & $1.91 \mathrm{E}-04$ & $1.15 \mathrm{E}-03$ & $4.00 \mathrm{E}-04$ & 0.92 \\
$\mathrm{MSY}$ & $8.81 \mathrm{E}+04$ & $8.44 \mathrm{E}+04$ & $-4.2 \%$ & $6.79 \mathrm{E}+04$ & $2.54 \mathrm{E}+05$ & $3.59 \mathrm{E}+04$ & 0.41 \\
$\mathrm{q} 2 / \mathrm{q} 1$ & $1.61 \mathrm{E}+02$ & $1.61 \mathrm{E}+02$ & $0.2 \%$ & $1.44 \mathrm{E}+02$ & $1.78 \mathrm{E}+02$ & $1.79 \mathrm{E}+01$ & 0.11 \\
\hline
\end{tabular}


true stock biomass. The validity of this assumption for the CPUE series used here is discussed in Hvingel et al. (2000) and will not be treated further in this paper.

The model assumes a logistic function for unexploited population growth, i.e. a simple quadratic stock-recruitment function. It also assumes that the carrying capacity and maximum intrinsic rate of growth are constant. Some of these assumptions may fail under some circumstances without invalidating all the results. Provided that the data includes a range of stock levels both above and below the true maximum yield level, it will not be serious if the population growth function is not exactly logistic, provided its differential is continuous and convexed upwards. Under such conditions, related errors will occur in both the extrapolated estimate of the carrying capacity and in the estimate of the intrinsic rate of growth, but the estimate of MSY will be nearly correct. However, if the data does not span the true MSY, more serious errors in estimating MSY are apt to result from failure of the model assumptions. For example, if carrying capacity or intrinsic rate of growth, or both, are not constant, performance of the model is hard to predict. Small random variations may not seriously affect the results, but large variations may make the model unstable. If there is a continuing trend in either parameter the model results may be completely confounded. Predation (e.g. Berenboim et al., 2000; Stefánsson et al., MS 1994) is considered to have a significant influence on shrimp population dynamics, and large changes in abundance of a major predator, the Atlantic cod Gadus morhua, are well documented within the time span of these data series. In particular, our first two years, 1976-77, were the last two years of a period when cod were relatively abundant in West Greenland waters (Anon., MS 1999). The physical environment (e.g. Koeller, 2000; Anderson, 2000) also affect shrimp populations and may be the cause of the rapid changes in abundance seen in some stocks (Anderson, 2000; Apollonio et al., 1986). Over the series of data used in this enquiry, the distribution both of the shrimp fishery and of the catches in the trawl survey has shifted southward (Hvingel, MS 1996). It has done so progressively over a number of years. This must imply that the carrying capacity in the northern grounds has fallen, and in the south has increased. However, we cannot automatically suppose that the total carrying capacity has stayed the same, so to that extent, the assumption in this assessment process of a constant carrying capacity seems perhaps questionable.

If the data contains little contrast and much random error, the stock-recruitment curve may not be easily fitted, and may overshoot the data and overestimate the MSY. However, the fishing mortality may be relatively well fixed by the slope at the origin of the stock-recruitment curve, and thus relatively constant. This appears to be what happened in our first set of runs, where the omission of some data points allowed the stock-recruitment curve to overshoot the data and produce elevated estimates of the MSY, although fishing mortality did not change much (Fig. 4 and 5). The MSY estimated from all the data - 96000 tons is itself greater than the highest annual catch over the history of the fishery, of about 87000 tons (Fig. 1), and may indicate that the stock-recruitment curve is not tightly defined by the data. However, in subsequent runs, which used all the data to fit the CPUE series, and only omitted serially the points from the fixed series, the variability was much reduced. This shows that the majority of the uncertainty in these results came from the uncertainty of the procedure for constructing the CPUE series.

When the experiment was repeated with the first two data points, viz. 1976 and 1977, permanently omitted, we obtained rather different results. The variation in the MSY was less, and the variation in sustainable fishing mortality and in standing stock was large. Furthermore, there was little difference whether the jackknife procedure included the GLM fitting of the CPUE series or whether points were simply omitted from a single series based on all the years' data (Table 2 ). This appears due to two separate effects.

The relative stability of the MSY may be because the data set, without those two years, better fits a quadratic stock-recruitment curve, and the MSY is more stably located. The extrapolation of the quadratic to the carrying capacity, and the concomitant calculation of the sustainable $\mathrm{F}$, then become more unstable. In this connection, we tested the correlation between the catch in one year, and the decrease in CPUE from that year to the next. This would be broadly expected to be positive, as large catches should tend to make the resource scarcer. In fact it was negative, indicating that a stock-recruitment model should be difficult to fit. However, when the points for 1976 and 1977, which combined relatively small catches with significant decreases in CPUE were omitted, the correlation became zero. Thus the data became more tractable for a stock-recruitment model. These two years were the last of a period in which cod were relatively abundant in West Greenland waters. Cod are predators on small shrimp, and may therefore reduce recruitment. So if cod were abundant, even moderate catches may have exceeded recruitment enough to 
reduce CPUE in the next year. This illustrates a possible difficulty in fitting a stock-recruitment model to a system in which the parameters are not free of trend. At the same time, the GLM fitting of the CPUE series seems to be affected by a poor fit in the two years 1976 and 1977, so that when those years are left out, the CPUE series fits better with less uncertainty (Fig. 7). Therefore, including the GLM fit in the jackknife procedure adds little variability to the results.

The 3-stage procedure used in the model assessment we tested here - fitting CPUE series to fleet data, combining them into a single series and then fitting a simple model of stock dynamics to the CPUE data - was not unusually complex in the domain of fishery resource management. The jackknife procedure we explored is a reasonable one for testing the reliability of such a procedure. Our results indicate enough uncertainty in the output to show that reliability of such procedures needs to be thoroughly checked before their results can be accepted for management decision making, and that the reliability may depend on specific local features of the data series used. Under the best circumstances, results may apparently be fairly reliable, but it appears that some parameters of the stock dynamics may be estimated with quite different reliability from others, and it is not always apparent which. The different steps in the process may contribute different degrees of uncertainty, so estimates of the uncertainty accrued in one step may be quite misleading as a guide to the total uncertainty.

Assessment methods based on aggregated stockproduction models have an intrinsic problem: a wellmanaged fishery in a stable environment, in which a sustainable catch close to the maximum is regularly taken with little variability in standing stock or fishing effort, provides little information on the parameters of the stock-recruitment function, which are therefore difficult to estimate reliably. Overcoming this difficulty by relying on long data series imposes a requirement for a stable environment free of significant mediumterm (i.e. of the order of decades) drift in the few simple parameters that define the stock-recruitment relationship - a requirement difficult to satisfy for shrimp stocks. Methods that use information on demographic population structure - such as virtual population analysis or delay difference models - can in theory avoid some of these difficulties by relying on details of the age structure of the stock or of the biology of the individual such as mortality, growth and recruitment, but usually have the limitation that they ignore the density dependence that is an important feature of aggregated models.

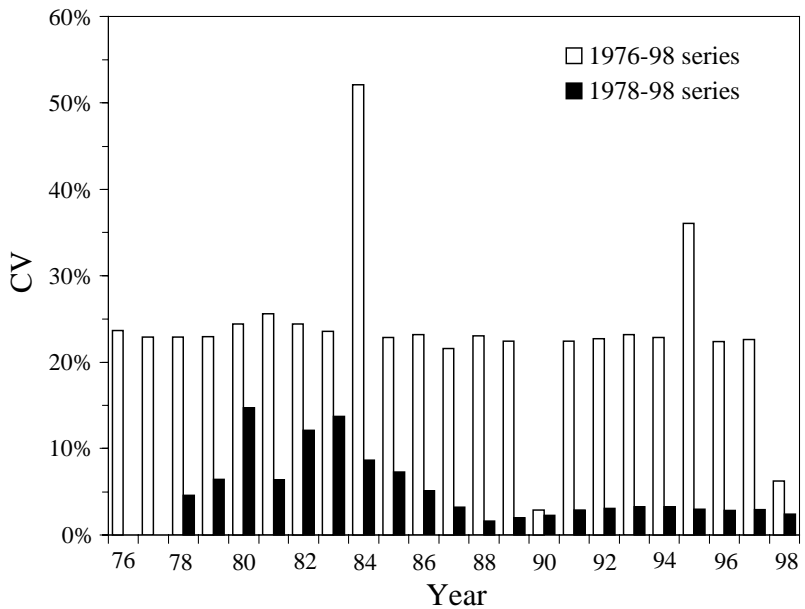

Fig. 7. Coefficient of variance (CV) of CPUE-indices constructed from the complete 1976-98 data series and from the reduced $1978-98$ series.

\section{Acknowledgments}

We thank the organisers of the Pandalid Shrimp Symposium for stimulating us to prepare this study for presentation and publication, and for patiently awaiting its submission. The modelling studies described would not have been possible without the long series of data carefully assembled and checked by our colleagues at Pinngortitaleriffik.

\section{References}

ANDERSON, P. J. 2000. Pandalid shrimp as indicators of ecosystem regime shift. J. Northw. Atl. Fish. Sci., 27: 1-10 (this volume).

APOLLONIO, S., D. K. STEVENSON, and E. E. DUNTON, Jr. 1986. Effects of temperature on the biology of the northern shrimp, Pandalus borealis, in the Gulf of Maine. NOAA Tech. Rep., NMFS, 42, 22 p.

ANON. 1999. ICCAT, International Commission for Conservation of Atlantic Tunas. Report for Biennial Period 1998-1999, Vol. 2.

MS 1999. Report of the North-Western Working group. 26 April-4 May 1999. ICES C.M. Doc., No. ACFM: 17.

BERENBOIM, B. I., A. V. DOLGOV, V. A KORZHEV, and N. A. YARAGINA. 2000. The impact of cod on the dynamics of Barents Sea shrimp (Pandalus borealis) as determined by multispecies models. J. Northw. Atl. Fish. Sci., 27: 69-75 (this volume).

BERENBOIM, B., and V. KORZHEV. MS 1997. On possibility to apply the Stefansson stock production model for assessment of shrimp (Pandalus borealis) stock in the Barents Sea. International Council. for the Exploration of the Sea, Baltimore, MD (USA), 25 Sep3 Oct 1997. Copenhagen-Denmark ICES 16 p.

BRADBURY, A., W. A. PALSSON, and R. E. PACUNSKI. 
1996. Stock assessment of the commercial sea cucumber Parastichopus californicus in the San Juan Islands, Washington State, USA. Int. J. Shellfish Res., 15: $785-786$.

CADRIN, S. X., S. H. CLARK, D. SCHICK, D. MCCARRON, and M. P. ARMSTRONG. 1999. Application of catch-survey models to the northern shrimp fishery in the Gulf of Maine. N. Am. J. Fish. Man., 19: 551-568.

CADRIN, S. X., and U. SKÚLADÓTTIR. MS 1998. Surplus production analysis of shrimp in the Denmark Strait, 1977-1998. NAFO SCR Doc., No. 117, Serial No. N4026, $18 \mathrm{p}$.

CARLSSON, D. M., and P. KANNEWORFF. MS 1998. Offshore stratified random trawl survey for shrimp (Pandalus borealis) in NAFO Subarea 0 and 1, in 1998. NAFO SCR Doc., No. 118, Serial No. N4027, 18 p.

CHEN,Y. and S. S. MONTGOMERY. 1999. Modelling the dynamics of eastern rock lobster, Jasus verreauxi, stock in New South Wales, Australia. Fish.Bull., 97: 25-38.

COOKE, J. G., and J. R. BEDDINGTON. 1985. The relationship between catch rates and abundance in fisheries. IMA J. Math. Appl. Med. Bio., 2: 1-15.

DONOVAN, G. P. (ed.). 1989. The comprehensive assessment of whale stocks: the early years. Rep. Int. Whal. Comm. Spec., Iss. 11.

EFRON, B. 1982. The jackknife, the bootstrap, and other resampling plans. Soc. for Indust. and App. Math., Philadelphia, $\mathrm{Pa}, 92 \mathrm{p}$.

GAVARIS, S. 1980. Use of a multiplicative model to estimate catch rate and effort from commercial data. Can. J. Fish. Aquat. Sci., 37: 2272-2275.

HILBORN, R., and C. J. WALTERS, 1992. Quantitative fisheries stock assessment. Chapman and Hall, New York, $570 \mathrm{p}$.

HORBOWY, J. 1996. The dynamics of Baltic fish stocks on the basis of a multispecies stock-production model. Can. J. Fish. Aquat. Sci., 53: 2115-2125.

HVINGEL, C., H. LASSEN, and D. G. PARSONS. 2000. A biomass index for northern shrimp (Pandalus borealis) in Davis Strait based on multiplicative modelling of commercial catch-per-unit-effort data (1976-1997). J. Northw. Atl. Fish. Sci., 26: 25-36.

HVINGEL, C. MS 1996. Geographical changes in the fishing pattern of Greenlandic shrimp trawlers in the Davis Strait, 1987-1996. NAFO SCR Doc., No. 110, Serial No. N2807, 5 p.

MS 1999. The Fishery for Northern Shrimp (Pandalus borealis) off West Greenland, 1970-1999. NAFO SCR Doc., No. 107, Serial No. N4087, 19 p.

KIMURA, D. K. 1981. Standardized measures of relative abundance based on modelling log (c.p.u.e.), and their application to Pacific ocean perch (Sebastes alutus). ICES J. Cons., 39: 211-218.
KOELLER, P. A. 2000. Relative importance of abiotic and biotic factors to the management of the northern shrimp (Pandalus borealis) fishery on the Scotian Shelf. J. Northw. Atl. Fish. Sci., 27: 21-33.

LUDWIG, D., and C. J. WALTERS. 1985. Are agestructured models approproate for catch-effort data? Can. J. Fish. Aquat. Sci., 42: 1066-1072.

1989. A robust method for parameter-estimation from catch and effort data. Can. J. Fish. Aquat. Sci., 46(1): 137-144.

MATHEWS, C. P., and M. SAMUEL. 1991. Management and research strategies in Kuwait's trawl fishery. In: Multispecies models relevant to management of living resources. N. Daan and M.P. Sissenwine (eds). ICES Mar. Sci. Symp., 193, p. 330-340.

NAFO. 2000. Scientific Council Reports 1999. 319 p.

NELDER J. A., and R. MEAD. 1965. A simplex method for function minimisation. Comput. J., 7: 308-313.

PRAGER, M. H. 1994. A suite of extensions to a nonequilibrium surplus-production model. Fish. Bull., 92: 374-389.

MS 1995. Users manual for ASPIC: A stockproduction model incorporating covariates, program version 3.6x. SEFSC Miami Lab. Doc., MIA-92/93-55.

PRAGER, M. H., C. P. GOODYEAR, and G. P. SCOTT. 1996. Application of a surplus production model to a swordfish-like simulated stock with time-changing gear selectivity. Trans. Am. Fish. Soc., 125: 729-740.

SAVARD, L., I. H. MCQUINN, and D. G. PARSONS. MS 1991. Investigating the potential of sequential population analysis for northern shrimp (Pandalus borealis) in Division 0A. NAFO SCR Doc., No. 71, Serial No. N1955, 12 p.

SCHAEFER, M. B. 1954. Some aspects of the dynamics of populations important to the management of the commercial marine fisheries. Bull. Inter-Am. Trop. Tuna Comm., 1(2): 27-56.

SKÚLADÓTTIR, U. 1979. Comparing several methods of assessing the maximum sustainable yield of Pandalus borealis in Arnarfjödur. ICES Rapp. Proc. Verb., 175: 240-252.

MS 1985. The sustainable yield of Pandalus borealis in the Denmark Strait area. NAFO SCR Doc., No. 15, Serial No. N949, 4 p.

STEFÁNSSON, G., U. SKÚLADÓTTIR, and G. PÉTURSSON. MS 1994. The use of a stockproduction-type model in evaluating the offshore Pandalus borealis stock of North Icelandic waters, including the predation of Northern shrimp by cod. ICES C. M. Doc., No. K:25, 13 p.

STEVENSON D. K., K. FRIEDLAND, and M. ARMSTRONG. MS 1997. Managing the U.S. Atlantic herring coastal stock complex for long-term sustainable yield. ICES C. M. Doc., No. DD:2, 21 p. 